\title{
Lung adenocarcinoma with mixed solid and crazy-paving appearances
}

 \\ Lily Diana Zainudin ${ }^{3}$
}

${ }^{1}$ Faculty of Medicine, Department of Radiology, Universiti Teknologi MARA, Sungai Buloh, Selangor, Malaysia

${ }^{2}$ Sunway Medical Centre, Subang Jaya, Malaysia

${ }^{3}$ Respiratory Unit, Pantai Hospital Kuala Lumpur, Kuala Lumpur, Malaysia

\section{Correspondence}

Roqiah Fatmawati Abdul Kadir, Faculty of Medicine, Department of Radiology, UiTM Sungai Buloh Campus, Jalan Hospital, 47000 Sungai Buloh, Selangor, Malaysia.

Email: roqiah@uitm.edu.my

\section{Funding information}

This article received no specific grant from any funding agency in the public, commercial, or non-profit sectors

\begin{abstract}
"Crazy paving" on CT images refers to the superimposition of ground-glass opacity and linear pattern resembling irregularly shaped paving stones. Initially, "crazy paving” was described as a pathognomonic sign of alveolar proteinosis. Subsequently, this pattern has been reported in a variety of disorders of the lung. We demonstrated CT images of lung adenocarcinoma demonstrating both solid and crazy-paving appearances.
\end{abstract}

\section{K E Y W O R D S}

adenocarcinoma, crazy paving, lung

\section{CASE}

"Crazy paving" refers to the superimposition of groundglass opacity and linear pattern on computed tomography (CT) images. "Crazy paving" was initially pathognomonic for alveolar proteinosis. Lung adenocarcinoma demonstrating both solid and crazy-paving appearances on CT is a rare occurrence.

A 69-year-old female non-smoker presented with prolonged cough, hemoptysis, and constitutional symptoms. The initial CT thorax revealed a heterogeneous mass in the right lower lobe with surrounding "crazypaving” appearance (Figure 1a and 1b). CT-guided biopsy revealed invasive, moderately differentiated lung adenocarcinoma (eGFR positive). She also developed right humeral pathological fracture. Some improvement was shown with Gefitinib, but progressed 6 months later. Repeat CT scan showed that the area of crazy paving was completely replaced by solid tumor, confirming that the "crazy paving" was tumor infiltration (Figure $1 \mathrm{c}$ and $1 \mathrm{~d})$.

Lung carcinoma usually appears as nodule (solid or subsolid) or mass on CT, rarely appears as ground-glass opacity or consolidation. ${ }^{1}$ Lung carcinoma with crazy paving as appeared in the Computed tomography is uncommon despite its recognized existence, and is usually caused by adenocarcinoma.

The solid component likely represents an invasive portion of the neoplasm, whereas the peripheral "crazy paving” may represent areas of lepidic growth. 

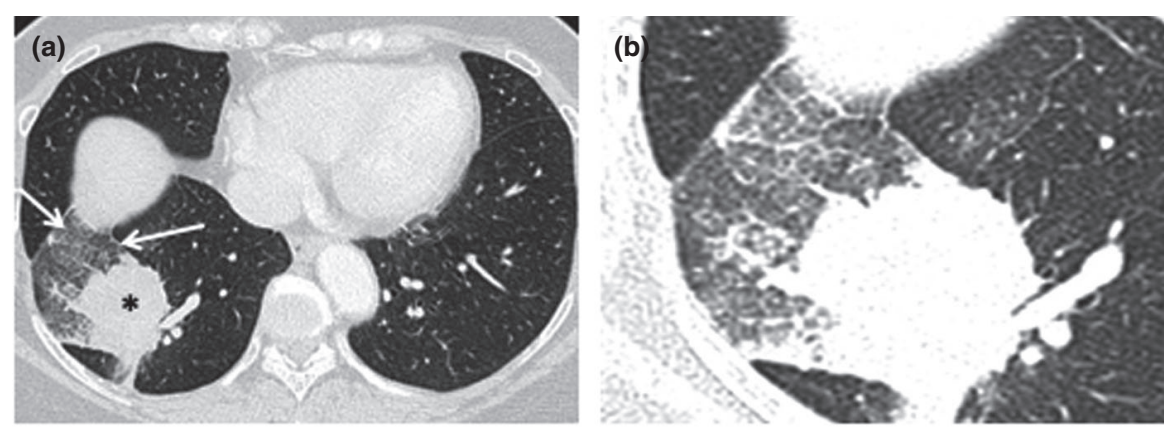

FIG URE 1 Selected thoracic CT images on axial view showing primary lung adenocarcinoma with both solid (asterisks) and "crazy paving" (white arrow) appearances (A \& B). B is a closeup view of A. The area of "crazy paving" is completely replaced by solid mass (C \& D) while maintaining the same demarcation confirming that the "crazy paving" is indeed tumor infiltration
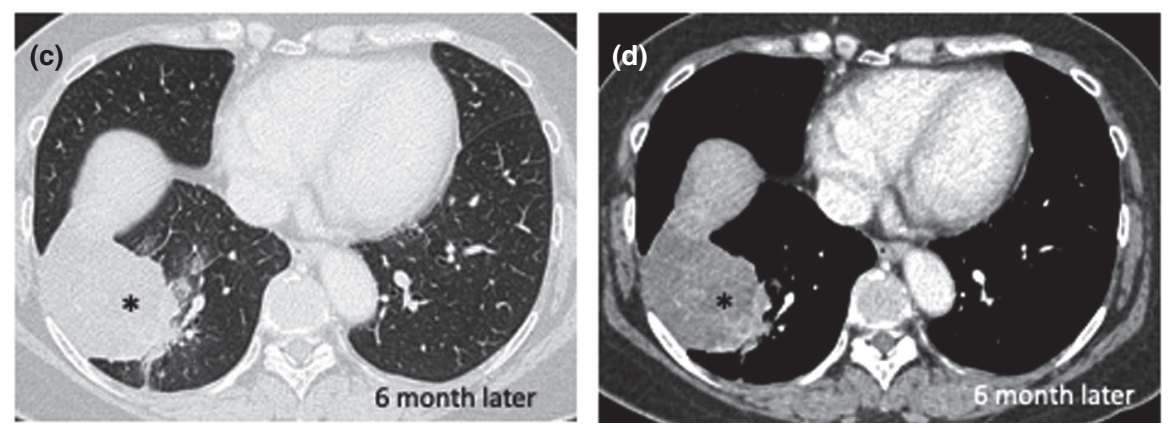

CONFLICTS OF INTEREST

All authors declare no conflicts of interest.

\section{AUTHOR CONTRIBUTIONS}

All authors contributed to the article.

\section{CONSENT}

Patient's consent has been signed and collected in accordance with the journal's patient consent policy.

\section{DATA AVAILABILITY STATEMENT}

Data sharing not applicable to this article as no datasets were generated or analysed during the current study.

\section{ORCID}

Roqiah Fatmawati Abdul Kadir (1) https://orcid. org/0000-0002-2772-8283
Mohammad Hanafiah (1) https://orcid.

org/0000-0003-4791-497X

\section{REFERENCE}

1. Ariozzi I, Paladini I, Gnetti L, et al. Computed tomographyhistologic correlations in lung cancer. Pathologica. 2013;105: 329-336.

How to cite this article: Abdul Kadir RF, Hanafiah M, Johari B, Zainudin LD. Lung adenocarcinoma with mixed solid and crazy-paving appearances. Clin Case Rep. 2021;9:e04847. https:// doi.org/10.1002/ccr3.4847 